\title{
Editorial: Families and Aging: From Private Troubles to a Global Agenda
}

In his foreword to a recent book on the state of social science research, Newby (2015) harkens back to C. Wright Mills' entreaty to elevate private troubles to public issues. Newby has argued that social scientists have long made the private public through creating the "ideas, insight, understanding and, crucially, debate where there are no simple solutions to our collective private troubles" (Newby, 2015, p. viii). Families are an exemplar of the challenges inherent in bridging the private and the public. We "know families" as members who are embedded in their private troubles; and we strive to know families as researchers and influencers of their public personas.

Articles in this special issue on Families and Aging in Global Context reflect the tradition of raising the issues and thinking critically about the debates. Around the world, discourses about families place them as the most important group for the social and supportive relationships of older adults (Keating, 2011). These discourses have been heightened in the face of poverty, pandemics, and changing family structures and obligations. Families today are viewed both as deficient in the care they provide and as compromised in their ability to do so (Uhlenberg \& Cheuk, 2008).

Population aging is a driver of much of the contemporary public debate about families. Families have come onto the public agenda as a backstop against concerns about unsustainable health, economic, and social care systems. Despite evidence of the flow of resources down the generations (Albertini \& Kohli, 2013), and calming voices about the sustainability of income security systems (Denton \& Spencer, 2011), we see remnants of apocalyptic demography (Gee \& Gutman, 2000) in the families' agenda. Further bolstering of the centrality of families comes from moral and sometimes legal imperatives to support older family members (Haberkern \& Szydlik, 2010). Whether based on cost or on compassion, families are a key theme in population aging.

Why global families? This special issue was developed to capture discussions across world regions on the place of older people in families. The impetus came from the belief that, in order to know families, we need to understand them in their various forms across (and within) regions. Family gerontology was developed from the standpoint of the global north. Yet a broader lens on laterlife families reveals diverse perspectives on their place in the lives of older adults. These perspectives variously extol the virtues of large, supportive, close-knit families; signal alarm about reduced family structure and caring capacity; and value intimacy at a distance. Such beliefs drive national policy approaches which have a significant impact on the family lives of older persons (The Global Social Initiative on Ageing Report on Activities, 2014).The articles in this special issue represent some of these global sensitivities in sub-Saharan Africa, Australia, Europe, China, Israel, and the United States. In making the private public, they begin to map family discourses and realities across cultures and settings.

\section{Discourses about Family Obligations}

Societal beliefs about families' responsibility for their members represent views of population aging and of older people. These, in turn, reflect values about how to address the challenges and about how benefits or burdens that accrue should be distributed. Van den Broek, Dykstra, and van der Veen speak to the likelihood of such views being incorporated into everyday life. They argue that attempts to change or enforce the way a society cares for its older members are more likely to be successful if they have moral plausibility. Moral plausibility occurs when there is congruence between societal admonitions and citizen beliefs about how burdens and benefits should be distributed.

Across world regions, societal discourses all point to the centrality of families, but their perspectives differ considerably. In both sub-Saharan Africa and China, there are explicit societal commentaries about the importance of families. In Africa, these are about the strengths of large, strong, supportive families; in China, about shoring up longstanding traditions of filial piety in the face of sharp declines in generational membership. Aboderin and Hoffman state that, in sub-Saharan Africa, the centrality, uniqueness, and indispensability of "the family" (sic) in support of older members is unquestionable. In China, beliefs about family responsibility also are strong, but there is concern about the erosion of filial piety arising from the decline of generational membership. Phillips and Feng argue that, in China, the ideal arrangement for family support remains multigenerational co-residence. Families are expected to ensure that elderly persons receive financial support, health care, and daily interaction with their children. Yet changes in family composition and growing inequities between rural and urban areas mean that such expectations are increasingly difficult to fulfill.

Discussions from more-developed countries also reveal expectations of family responsibility. Roberto and 
Blieszner identify a persistent North American ideological code of families as nuclear, close-knit, and co-resident, and as ideally suited to caring for their members. They argue that families permeate the policy agenda. Yet the reification of this particular family structure is at odds with the fact that such family types are rare in the United States.

Family discourses in both Europe and Australia are couched in terms of the withdrawal of public support for care that results in families by default. Van den Broek, Dykstra, and van der Veen discuss conflicting discourses between families and the state vis-à-vis responsibility for care of older adults. In the Netherlands, care ideals from the perspective of family members are to have less family and more state involvement. In contrast, the state wants more family involvement and fewer public interventions. The authors present a narrative of loss in which the state formerly reduced the pressure on families by supporting older adults but now is retreating from a social welfare approach.

In Australia, the place of families in addressing population aging is not a central element of public debate. Biggs, Carr, and Haapala state that the need to address population aging is becoming accepted in Australia policy circles, but no policy attention is focused on family roles of older adults. Rather, Australian policy discussions are based on individualistic assumptions that older people should be active and independent. Biggs et al. describe this approach as "economic instrumentalism". It negates legitimate age transitions associated with work such as retirement, while personal development and age-related life priorities are in danger of being ignored. Importantly from the perspectives of the families' agenda, these authors suggest that the approach also forces people into dual roles of employment and care that are unacknowledged. Presumably older adults who are active and independent don't need support from their family members. Biggs et al. conclude that the mismatch between policy initiatives and familial and personal priorities constitutes a new social risk.

These discourses about population aging have brought family obligations into public view. They highlight beliefs about the strong caring capacity of particular family types, and about their caregiving deficits. Public policy discourses reflect an indirect but nonetheless powerful valuing of "families by default". Both directly and indirectly, the discourses lead to the conclusion that despite public concern about population aging, care and support remain private family troubles.

\section{Family Resources and Constraints}

Regardless of the discourses about obligation, families are constrained in their ability or willingness to provide support to older members. The nature and the magnitude of these constraints differ. Aboderin and Hoffman frame their discussion around the vulnerability and incapacity of older persons resulting from poverty and difficult living situations. In sub-Saharan Africa, older persons may have little access to family care because of the migration of young people to urban areas and of poverty in co-resident households. In these settings, care most likely flows down the generations, especially to vulnerable grandchildren. China also has experienced a reduction in co-residence among generations. Cong and Silverstein describe a pattern of contingent co-residence in which adult children return home when parents are most vulnerable. Thus children modify but do not violate obligations related to filial piety, acting as latent resources which are activated when the needs of parents become acute. Constrained willingness to care is illustrated in de Jong Gierveld's research on older couples in the Netherlands who were "living apart together". About half of LAT couples stated that they would not provide care to their partner, evidence of contingent commitments among some late-life couples. Roberto and Blieszner's analysis of pluralistic families also showed resource limitations among couples. Those whose prior relationships had been strained were more likely to engage in potentially harmful caregiving behavior.

Monolithic assumptions about availability of family care also are being challenged. Katz, Lowenstein, Halperin, and Tur-Sinai reviewed data from Europe and Israel to illustrate variety in family resources that parents and their adult children are able to draw on. They found that the most common pattern was "downward familialism" in which support flowed from older parents to adult children. "Ascending familialism" was associated with a higher age of parents, health problems, and with higher levels of resources among adult children. Almost one third of families were characterized by autonomous patterns of living at a distance and minimal supportive exchanges. Roberto and Blieszner also challenge researchers to look beyond static assumptions about sources of care. They question whether having more adult children is good caregiving insurance, stating that there is little empirical literature that assesses the added-value of having multiple children providing care versus having one primary caregiver.

\section{Changing the Boundaries of What is a Family}

One of the tenets of the "declining family capacity" discourse is that upcoming cohorts of older adults have less potential for support as a result of declining birth rates (Carrière, Keefe, Légaré, Lin, \& Rowe, 2007). The shrinking nuclear family and especially small numbers of adult children are the focus of this concern. Evidence from empirical research on caregiving that adult children are the largest group of caregivers (Sinha, 2013) suggests 
that in the global north, the tightly bounded family is the appropriate focus of concern about family support capacity. Yet pluralistic models of family life are increasingly common. In reference to the United States, Roberto and Blieszner state that structural flexibility is likely a more common feature of families than scholars have acknowledged. They argue that we must look beyond spouses and adult children to see, for example, whether multigenerational beanpole families have enhanced capacity to support each other; under what circumstances step-parents are incorporated as family members; and how LGBT individuals create families. Our global lens suggests that a more expansive debate around family boundaries is warranted. In China, how does delayed or deferred co-residence of adult children and aging parents violate norms of generational co-residence (Phillips \& Feng; Cong \& Silverstein)? In Europe, do new forms of couple relationships such as living apart together influence norms of intimacy and commitment among couples and their kin networks (De Jong Gierveld)? What are the boundaries around African families when it comes to issues of commitment and flows of support (Aboderin \& Hoffman)? Across the globe, does "doing family" ensure the inclusion of older members?

\section{A Global Families Research Agenda}

The authors of Families and Aging in Global Context collectively have created a critique of societal perspectives on families of older adults; presented empirical findings about family resources, constraints, and the flow of resources among family members; and argued the need to rethink the boundaries around what's a family. Together, their work adds considerably to how we know families. But as social scientists, our task is not complete with the creation of a knowledge base. As Maclean and Roberts (2015, p. 128) state: "Contemporary work in the social sciences has an additional, perhaps even more important, role to play - namely in the search not only for answers to known problems, but in going on to develop the next set of questions."

There are many questions raised by the authors whose articles comprise this issue. To organize these into a global research agenda is daunting. However, we believe Aboderin and Hoffman's cross-cutting themes for a research agenda on families of older adults in Africa incorporate many of the core questions and would work well across world regions. They suggest four cross-cutting perspectives to inform inquiry into the realities of aging families:

- An interpretive approach that interrogates beliefs about family structure and quality.

- Critical engagement with salient theoretical or conceptual ideas in the global gerontological literature about family ties in later life.
- Incorporating the heterogeneity of experiences of aging families.

- Placing experiences of families of older adults within the context of global trends such as international migration and widening inter- and intra-country inequality.

Families and Aging in Global Context is given to the researchers, policy makers, and practitioners who will ask the critical questions and move forward our knowledge. May you enhance the ways that we know families towards a better quality of life for older people and the variety of families in which they live their lives.

Norah Keating and Jenny de Jong Gierveld Guest Editors

\section{References}

Albertini, M., \& Kohli, M. (2013). The generational contract in the family: An analysis of transfer regimes in Europe. European Sociological Review, 29(4), 828-840.

Carrière, Y., Keefe, J., Légaré, J., Lin, X., \& Rowe, G. (2007). Population aging and immediate family composition: Implications for future home care services. Genus, LXIII(1), 11-31.

Denton, F. T., \& Spencer, B. G. (2011). Age of pension eligibility, gains in life expectancy, and social policy. Canadian Public Policy, 37, 183-200.

Gee, E. M., \& Gutman, G. M. (Eds.). (2000). The overselling of population aging: Apocalyptic demography, intergenerational challenges, and social policy. Toronto, ON: Oxford University Press.

Haberkern, K., \& Szydlik, M. (2010). State care provision, societal opinion and children's care of older parents in 11 European countries. Ageing and Society, 30(2), 299-323.

Keating, N. (2011). Critical reflections on families of older adults. Advances in Gerontology, 24(2), 343-349.

Maclean, M., \& Roberts, C. (2015). Numbers and questions: The contribution of social science to understanding the family, marriage and divorce. In J. Michie \& C. L. Cooper (Eds.), Why the social sciences matter (pp. 128-142). Basingstoke, UK: Palgrave Macmillan.

Newby, H. (2015). Foreword. In J. Michie \& C. L. Cooper (Eds.), Why the social sciences matter (pp. vii-iix). Basingstoke, UK: Palgrave Macmillan.

Sinha, M. (2013). Spotlight on Canadians: Results from the General Social Survey. Statistics Canada, Catalogue no. 89-652-X - No. 001.

The Global Social Initiative on Ageing Report on Activities (2014). Downloaded March 11, 2015 from http://wun.ac.uk/ files/2014jun3_gsia_2013_final_report.pdf.

Uhlenberg, P., \& Cheuk, M. (2008). Demographic change and the future of informal caregiving. In M. Szinovacs \& A. Davey (Eds.), Caregiving contexts. Cultural, familial and societal implications (pp. 9-33). New York, NY: Springer. 